\title{
Image Segmentation Based on Generic Shape Algorithm
}

\author{
Karthik. B, Sriram. M, Mohan Raj. R.
}

\begin{abstract}
Level set based techniques are widely used for the aggregation of images. Prior advantage on the form of the segmentation contours. The level set version of the effective size models can be obtained by offering the previous type with the chan-vese model. The higher level model can be taken into consideration for earlier form capacity pretty efficaciously and is used for multiphase segmentation. The GSA (periodic shape Algorithm) will also be more classified into the Regional and Contour GSA for a good integrated application, the vicinity of a patriarchal graph-reduce scheme of optimization is developed, for its worldwide implementation of use. of the local GSA to get hold of desirable international segmentation outcomes, and the nearby one using the Contour GSA to refine limitations of world outcome.
\end{abstract}

Keywords : Level set, multiphase segmentation, active shape models.

\section{INTRODUCTION}

The GSA (periodic shape Algorithm) will also be more classified into the Regional and Contour GSA for a good integrated operation, the vicinity of a patriarchal graph-reduce scheme of computing is developed, for its worldwide implementation of use., corresponding to combo random-field gadgets [1], the graph-reducing and spectral technique [2], and the variational texture segmentation objects $[3,4]$, just to say more than one. In the variational techniques, when you consider that the paintings of Mumford and Shah's photograph mannequin [3], many extensions and residences have been studied. The Chan-Vese mannequin [4] is a well-known work with a fantastic implementation utilizing stage set technique [5,6]. Level set is an easy and flexible method for computing and inspecting the motion of an interface in two or 3 dimensions. It has additionally been largely used to take a look at and display the boundary of gadgets hidden in a photograph. The occurrence of degree set is that its convergence is impartial of the initialization and it can cope with topological modifications of curves routinely. Chan-Vese mannequin has been prolonged to multiphase segmentation [7]. In multiphase segmentation, there is an instability limitation related to figuring out the quantity of stages Which is required to programme the picture properly. One method for preventing the selection of the amount of rates is to give many original contours with the wish that the

Revised Manuscript Received on August 22, 2019.

Karthik.B, Assistant Professor, Department of Electronics And Communication Engineering,, Bharath Institute of Higher Education and Research, Chennai, India. : karthik.ece@ bharathuniv.ac.in

Sriram.M Assistant Professor, Department of Electronics And Communication Engineering,, Bharath Institute of Higher Education and Research, Chennai, India.msr1sriram@gmail.com

Mohan Raj.R., Assistant Professor, Department of Electronics And Communication Engineering,, Bharath Institute of Higher Education and Research, Chennai, India.dspmohanraj@gmail.com required contours remain as efficient as possible. However, if there are higher levels than they are decided to take a look at,this can occasionally cause disorders with unnecessarily isolating one item to a couple of area.

On this document, we recommend a Grade Set variant of the Energetic Form Designs to give Form Previous and to incorporate this Form Previously with the Chan-Vese Multiphase Segmentation Model. The kind of components may want to account for numerous types (boundary or nearby) of photo terms of pretty quiet a few nature (edges, intensity homes, texture, motion, and so on.), a predominant impediment A pattern of active form. In addition, the imperative and inherent holdings of the volume scheme are laid at the top due to the current capacity to account for topological modifications on the same time being ready to introduce previous form abilities will also be maintained inside the meanwhile.[1-5]

\section{PROPOSED SYSTEM}

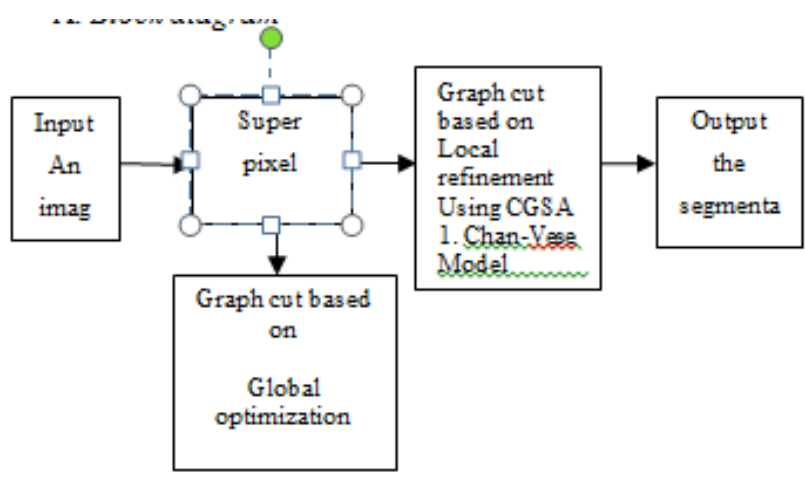

Fig .1. Block Diagram

Photograph segmentation is used to split a photo into several "meaningful" ingredients. There are fundamental motives, the first is that the content material kind of graphics is too super, and the second one is that there may be no benchmark common to gauge the performance.

\section{A.The normalized cut framework}

There are plenty of previous works about photograph segmentation, pleasant survey assets would be found in. From those surveys, we'd without difficulty separate the image segmentation systems into three distinct guides (1) function-space founded technique, (2) photo-domain situated technique, and (3) component-primarily based method. The function-house located device consists of steps, feature extraction and clustering. Characteristic extraction is the technique to seek out some trends of each pixel or of the community spherical every pixel, for example, pixel cost, pixel color issue, windowed common pixel fee, windowed variance, legislation's filter feature, Tamura characteristic,

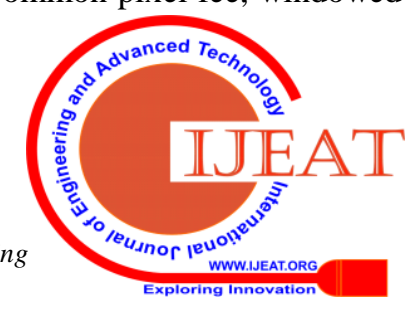


and Gabor wavelet characteristic, and many others.

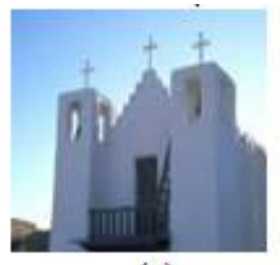

(a)

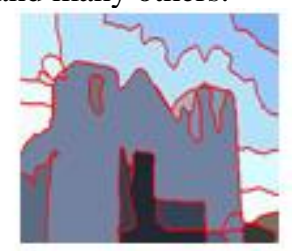

(b)

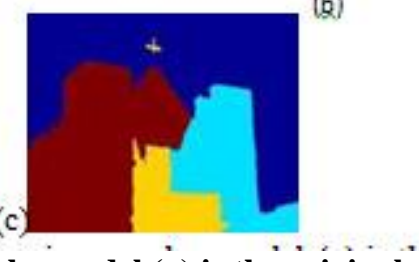

Fig.2. Gaussian combo model (a) is the original snapshot, (b) is the segmentation effect founded on, and (c) is the influence from.

After we get some symbolic houses around every and each pixel, clustering procedure is executed to separate the photograph into a number of "considerable" substances set up on these properties. This is rather like what we've got attempted to used rules's function mixed with okay-approach clustering set of rules. [4]

There are moreover many sorts of clustering algorithms, for illustration, Gaussian mixture model, suggest shift, and the only in each of our assignment, "normalized lessen". Image-place primarily based method goes through the picture and locates the boundary between segments by the usage of some ideas. The number one attention to separate two pixels into one-of-a-type segments is the pixel price alternate, so this form of techniques couldn't cope with textures superb. Cut up and merge, location developing, and watershed are basically the maximum preferred methods on this category. The threshold-based image segmentation method, which incorporates factor detection and element linking.[5]

Finally the brink detection manner makes always go through the over-segmentation trouble. In our venture, we undertake the "normalized cut framework" for photo segmentation, which reveals the first-rate slicing course from the worldwide view (the whole image view) instead of via local thresholds and is anticipated to have higher segmentation consequences than other methods. The basic idea of normalized reduce framework and its mathematical derivation is provided, and about the capabilities we undertake for similarity measurement. It's perform our photograph segmentation techniques on several sorts of photograph and display the outcomes. And sooner or later, we'll provide dialogue and conclusion approximately our assignment, and also list a few future works that we are able to preserve going for the advanced research purposes.[6]

The normalized cut of the image segmentation hassle can also be obvious as a graph idea quandary. Graph concept is a charming math topic which fashions math troubles into arcs (edges) and nodes. Even although it's difficult to provide a reason for graph concept in this undertaking file, we offer useful examples to provide readers extra ideas about what it might probable do.[7] This shape of graph is referred to as "weighted graph", and is most possibly adopted with the useful resource of internet researchers. The preceding picture became as soon as results easily segmented by using manner of our algorithm, but that photo ought to have been segmented simply as true with the aid of loads simpler machine. [8]

\section{B. Measurement reduce framework the usage of GSA}

Within the normalized reduce framework, we additionally mannequin the image right into a graph. We model each pixel of the picture as a node in the graph, and set a part among two nodes if there are similarities between them. The normalized reduce framework consists of steps: similarity dimension and normalized lessen manner.

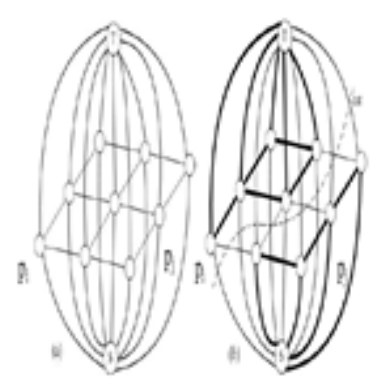

Fig.3. A simplified global map, and (a) is the graph mannequin of (b), which gadgets every and each county as a node

and if counties are related, a part is drawn between them. The global estimation method first performs superpixel fore-processing to reduce matrix multiplication in relation to retaining the maximum number of conventional picture schemes.. The nearby courting among super-pixels is defined as: two super-pixels are buddies if any pixel in a single super-pixel is adjoining to a pixel inside the unique. [9-13]

The motive of this step is to compute the similarity between pixels and this well worth is ready as the burden on the threshold. In order to mannequin the whole similarities of an snapshot, all pair pixels will include an aspect, which means if an photo includes a pixels, there can be thoroughly half of edges within the corresponding graph. This form of graph is known as "whole graph" and wishes a good sized reminiscence region. To simplify the quandary, normally we set edges among nodes. The super-pixel consists of a right picture segmented with the aid of GSA set of rules. Only whilst their distance is smaller than an awesome threshold Edges with blue colour suggest weak similarities, while edges with red shade mean robust similarities. Edges with blue color mean vulnerable similarities, on the identical time edges with red colour imply strong similarities. This is a related graph due to the truth that each pixel would possibly cross through the edges to arrive all different pixels else. The term "reduce" way removing a fixed of edges to make the graph "unconnected", and the reduce value is the total weights on this set of edges. For example, if we take away all the blue edges in the nodes with white colour will probable be "unconnected" to the nodes with dark coloration, and now we're saying the graph has been separate into associated graph (the outside darkish crew and the interior white team).

So, from the graph concept, the image segmentation scenario is modeled as graph lessen catch 22 situation. However there are various styles of slicing course we can adopt to separate the image into segment, we ought to comply with a few criterions 

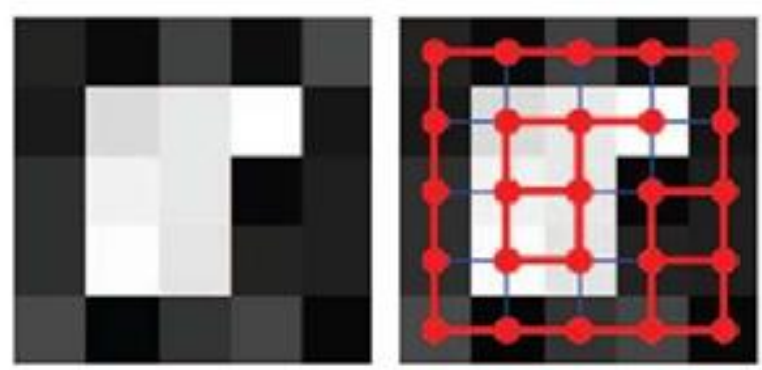

Fig.4. Noise images (a) is the same old photograph, and in (b) this photo has been modeled as a graph: each and each pixel as a node, and 2 nodes have an component furnished that their distance is identical to at least one.

Consider that the weights on edges have the similarity meaning among pixels, so if we need to separate pixels into two exceptional organizations, their similarity is expected to be small. Three forms of reducing criterions had been proposed in updated years: (1) minimum cut, (b) minimal ratio reduce, and minimum normalized reduce has been proved to keep each excessive alternate among segments and high similarities internal each segments. So in our mission, we undertake the normalized reduce framework.[14-17]

\section{C.The system for finding normalized reduce}

In these subsections, we'll present the mathematical derivation and set of rules implementation about the best manner to in finding the normalized reduce in a given image. The ordinary derivation is presented in and here I simply provide a short summary. A graph $\mathrm{G}=(\mathrm{V}, \mathrm{E})$ may be partitioned in disjoint devices, $\mathrm{A}, \mathrm{B}, \mathrm{AUB}=\mathrm{V}, \mathrm{A} \cap \mathrm{B}=0$, with the aid of actually doing away with edges connecting the two components. The diploma of dissimilarity between those two portions also can be computed as whole weight of the edge that have been eliminated. In graph theoretic language, it is known as the reduce:

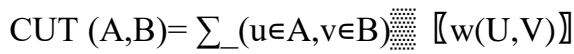

The normalized cut then could be defined as:

$\operatorname{NCUT}(\mathrm{A}, \mathrm{B})=$

$(\mathrm{CUT}(\mathrm{A}, \mathrm{A})) /(\mathrm{ASSO}(\mathrm{A}, \mathrm{V}))+(\mathrm{CUT}(\mathrm{B}, \mathrm{B})) /(\mathrm{ASSO}(\mathrm{B}, \mathrm{V})) \ldots \ldots$

Where $\left.\mathrm{ASSO}=\sum(\mathrm{u} \in \mathrm{A}, \mathrm{v} \in \mathrm{B})\right)_{\mathrm{w}} \mathrm{w} \mathrm{W}(\mathrm{U}, \mathrm{V})$ is the total connection from nodes in A to all in the graph, and ASSO $(\mathrm{B}, \mathrm{V})$ is likewise described. In the same spirit, we can describe a measure for total normalized association within groups (a measure for similarities inside each group) for a given partition:

$\operatorname{NASSO}(\mathrm{A}, \mathrm{B})=$

$(\mathrm{ASSO}(\mathrm{A}, \mathrm{B})) /(\mathrm{ASSO}(\mathrm{A}, \mathrm{V}))+(\mathrm{ASSO}(\mathrm{B}, \mathrm{B})) /(\mathrm{ASSO}(\mathrm{B}, \mathrm{V})) \ldots$ ......(2.1)

Hera an important relation with $\operatorname{NCUT}(\mathrm{A}, \mathrm{B})$ and $\operatorname{NASSO}(\mathrm{A}, \mathrm{B})$ could be derived as followed:

$\operatorname{NCUT}(\mathrm{A}, \mathrm{B})=$

$(\mathrm{CUT}(\mathrm{A}, \mathrm{B})) /(\mathrm{ASSO}(\mathrm{A}, \mathrm{V}))+(\mathrm{CUT}(\mathrm{A}, \mathrm{B})) /(\mathrm{ASSO}(\mathrm{B}, \mathrm{V})) \ldots \ldots$ ...(2.2)

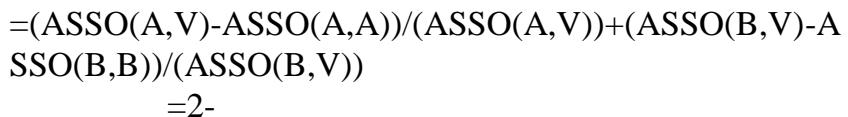

$(\operatorname{ASSO}(\mathrm{A}, \mathrm{A})) /(\operatorname{ASSO}(\mathrm{A}, \mathrm{V}))+(\mathrm{ASSO}(\mathrm{B}, \mathrm{B})) /(\mathrm{ASSO}(\mathrm{B}, \mathrm{V})) \ldots$ .....(2.3)

$=2-\mathrm{NASSO}(\mathrm{A}, \mathrm{B})$
This is the normalized graph cut, according to the function of relation with the image segmentation level set methods.

D.Implementation Algorithm

The normalized cut problem has been derived right into a trendy eigenvector trouble. In this subsection, we just listing the maximum essential equations, and readers where interested in the total process may want to get greater in an algorithm.

Expect now we wish to split a picture $\mathrm{V}$ with measurement $\mathrm{M}$-with the resource of- $\mathrm{N}$ into two materials, we should outline matrices: $\mathrm{W}$ and $\mathrm{D}$, every of measurement (MN)-by using manner of-(MN). The matrix $\mathrm{W}$ is the similarity matrix with issue $\mathrm{Wi}, \mathrm{j}$ as the similarity between the jth pixel. The matrix $\mathrm{D}$ is a diagonal matrix and every diagonal detail di includes the sum of all the factors within the jth row in $\mathrm{W}$. With these matrices, discovering the minimal normalized reduce of photograph $\mathrm{V}$ into two elements $\mathrm{A}$ and $\mathrm{B}$ is identical to solve the equation as adopted:

$\operatorname{MinNCUT}(\mathrm{A}, \mathrm{B})=\operatorname{Miny}(\mathrm{y}(\mathrm{D}-\mathrm{W}) \mathrm{y}) / \mathrm{yDy}$.

In which $\mathrm{y}$ is an (MN)-with the aid of-1 vector with each and each detail indicating the attribute of each pixel into the two groups. Would be extra simplified right right into an everyday eigenvector challenge as followed:

$(\mathrm{D}-\mathrm{W})=\lambda \mathrm{Dy} \ldots \ldots \ldots \ldots . . .(2.6)$

The eigenvector $y$ with the second one smallest eigenvalue is selected for photo segmentation. The element values in y can incorporate all actual numbers, so a threshold must be described to separate pixels into organizations. Determine the vector there are several styles of ways to define this threshold, as an example, 0 , suggest, value, and medium cost among all of the factors in y. In our project, we use those three kind of thresholds to get 3 exceptional y. If a detail in y is greater than the brink, we set the detail as 1 , otherwise as $-b$. The value $b$ is defined as:

$\mathrm{B}=\left(\sum \mathrm{yi}>\right.$ threshold di $) /\left(\sum \mathrm{yi} \leq\right.$ threshold di $)$

\section{E. Feature extraction and similarity measurement}

Since we need to segment special objects into distinct areas, step one we need is to compute the function of every pixel and compute the similarity of each pair of pixels before we separate them. We have several strategies to calculate picture features inclusive of luminance for non-texture snap shots and texton, an effective device we use for texture pictures. We also discover a few papers the use of texton and contour facts and get better overall performance while ensuing in complicated computation. In our technique, we undertake luminance (RGB) primarily based, texton based totally, and the adaptive method combining luminance and texton for characteristic computation. After extracting capabilities of each pixel, we used a few standard distance measure methods to remember the similarity among each pair of pixels.[18]

\section{F.Matching}

In segmenting first calculate the brink cost of original picture .It's far associated with the capabilities of picture. Then calculate the threshold fee of question picture after which evaluate with original value. If each are equal, then the given question photograph is original picture in any other case unique one.

The segmentation, in view that our foreground and historical past regions both have uniform

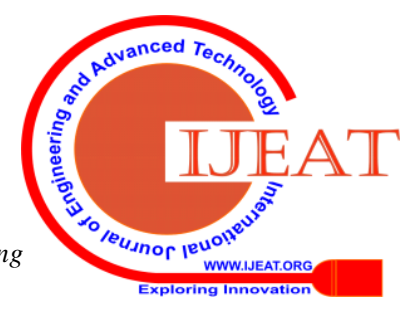


depth earlier than noise is delivered.[19]

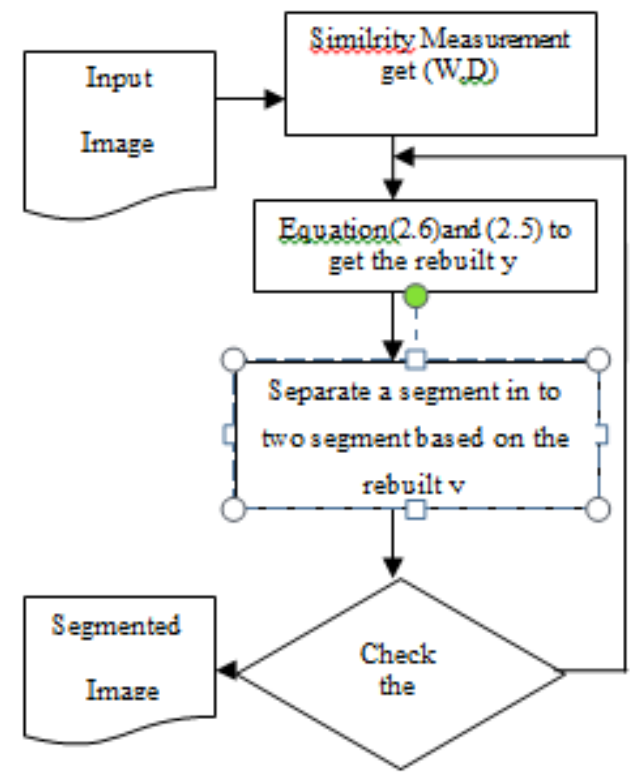

Fig .5. The flowchart of the normalized cut framework A fundamental consideration in many useful purposes is the automated resolution of parameter worth and parameters had been selected manually to present qualitatively good segmentations for each and every scan picture. In some circumstances, where we anticipate working on fairly homogeneous information, we might be capable to get away with a hardcoded set of parameters.

\section{EXPERIMENTAL RESULTS}

In order to verify the effectiveness of our mannequin on dual-phase differentiation, we have carried out tests on the more than one face contour production. The instruction set for our model is from the Oral Face computer system.. [20]

\section{G.Simulation Overview}

Simulations were performed by using MATLAB .By using MATLAB function first convert RGB image to gray image. Then gray image is given to Harris function and it detects the corners of the given image. After that we calculated threshold value of image. Here for selecting input images using GUI window.

\section{H.Simulation Results}

1.Input image is given to the system. Here we use group of photo as input image. It is an original image.

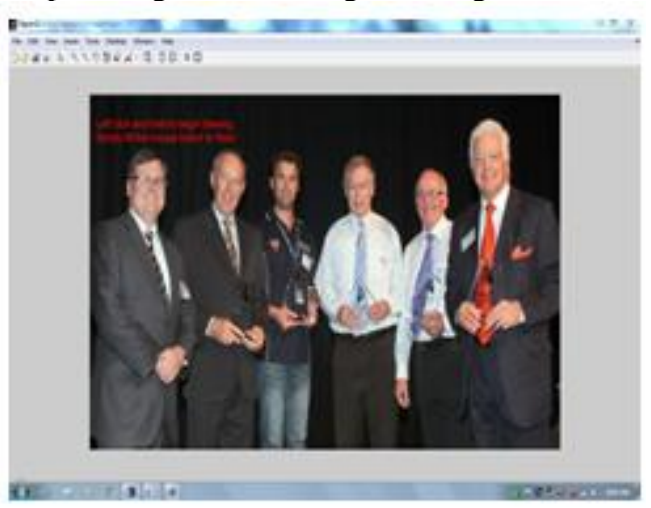

Fig .6. Input Color Image

2.The mean generic $s$ in the masked region and regions in color will be dark in the Generic Shape

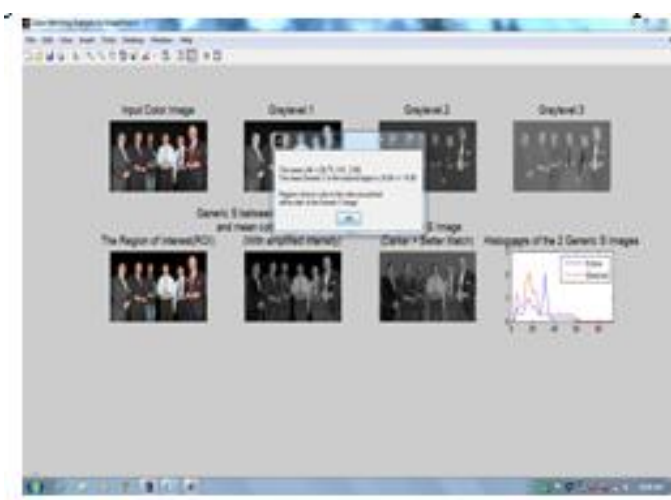

Fig .7. Gray level Analysis

3. First examine the histogram. Then find pixels within this Generic S (from average color in the region of interest).

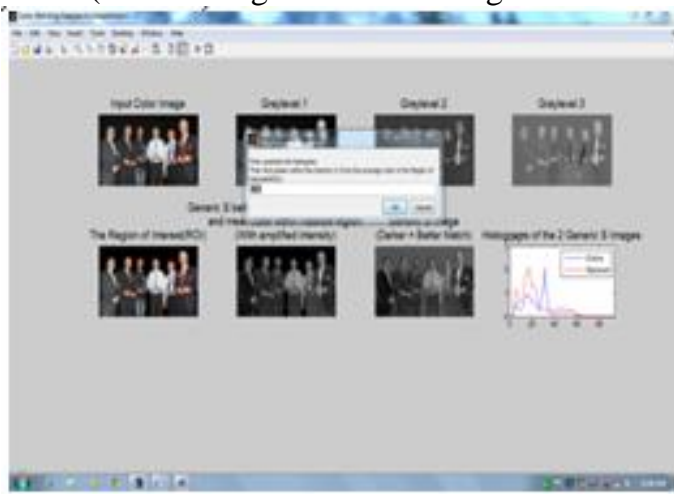

Fig .8. Average color in the Region Of Interest(ROI) 4.Done!.The example image has finished. Regions close in color to the color you picked will be dark in the shape $S$ images

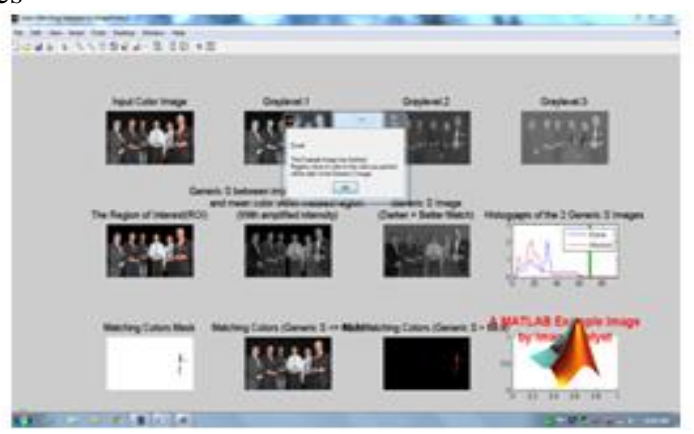

Fig .9. Color variation in Generic Shape images

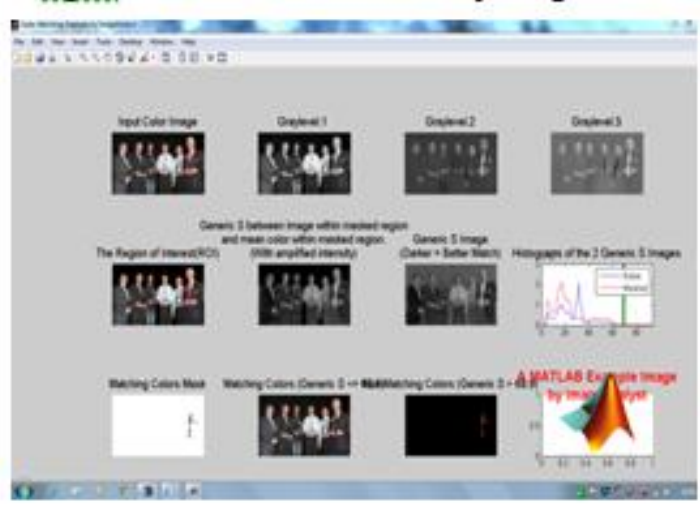

Fig .10. output Images 


\section{CONCLUSION}

An engaging photo fragmentation gadget that captures the image nature of the know-how and the GSA data stated through the use of the person under the chart lessen set up structure. Two types of GSA knowledge are intended in a patriarchal development strategy, where R-GSA is used within worldwide scheduling to ensure greater global results, and C-GSA is used within the community gadget to refine obstacles to global results. Superpixel proto-processing strategies in global development and only because a subgroup of pixels in local computing accelerates the process.. The experiments show the effectiveness and precision of our equipment. Now, we've suggested outstanding usual shape capacity for segmentation, and then we'll use the shape or region know-how of the ancient beyond..

\section{REFERENCES}

1. Kongkham, D. \& Sundararajan, M. 2019, "Distributed wideband sensing method for faded dynamic spectrum access", International Journal of Innovative Technology and Exploring Engineering, vol. 8, no. 10 , pp. 4309-4312.

2. Balaji, S., John Paul Praveen, A. \& Mohanraj, R. 2019, "Recognizable proof and analysis of palm print in biometric authentication system using bayes techniques", International Journal of Innovative Technology and Exploring Engineering, vol. 8, no. 9 Special Issue 3, pp. 1126-1129.

3. Kavitha, G., Priya, N., Velvizhi, R. \& Allin Geo, A.V. 2019, "Parallel computation in correspondence and signal processing", International Journal of Innovative Technology and Exploring Engineering, vol. 8, no. 9 Special Issue 3, pp. 1136-1139.

4. Hema, R., Sundararajan, M. \& Balaji, S. 2019, "Smartphone control robot with automatic firing gun", International Journal of Innovative Technology and Exploring Engineering, vol. 8, no. 9 Special Issue 3, pp. 625-627.

5. Kaliyamurthie, K.P., Sundar Raj, B., Velvizhi, R. \& Shanmugapriya, K. 2019, "Dual band paper substrate CPW antenna for wireless applications", International Journal of Innovative Technology and Exploring Engineering, vol. 8, no. 9 Special Issue 3, pp. 605-608.

6. Geo, A.V.A., Arunachalam, A.R., Michael, G. \& Elankavi, R. 2019 , "Evaluating architecture using compact modalities", International Journal of Innovative Technology and Exploring Engineering, vol. 8, no. 9 Special Issue 3, pp. 836-838.

7. Theivasigamani, S., Jeyapriya, D. \& Anita Davamani, K. 2019, "Anamoly analyzing and exploring for wireless sensor networks", International Journal of Innovative Technology and Exploring Engineering, vol. 8, no. 9 Special Issue 3, pp. 1116-1118.

8. Jeyapriya, D., Theivasigamani, S., Velvizhi, R. \& Nandhini, P. 2019, "Program detection in wireless feeler networks", International Journal of Innovative Technology and Exploring Engineering, vol. 8, no. 9 Special Issue 3, pp. 1194-1195.

9. Gowri Sankaran, B., Karthik, B. \& Vijayaragavan, S.P. 2019, "Image compression utilizing wavelet transform", International Journal of Innovative Technology and Exploring Engineering, vol. 8, no. 10, pp. 4305-4308.

10. Gowri Sankaran, B., Karthik, B. \& Vijayaragavan, S.P. 2019, "Weight ward change region plummeting change for square based image huffman coding", International Journal of Innovative Technology and Exploring Engineering, vol. 8, no. 10, pp. 4313-4316.

11. Hema, R., Sundararajan, M. \& Balaji, S. 2019, "Smartphone control robot with automatic firing gun", International Journal of Innovative Technology and Exploring Engineering, vol. 8, no. 9 Special Issue 3, pp. 625-627.

12. Rangaswamy, K. \& Rajabhushanam, C. 2019, "Congestion control in wireless network using TCP friendly rate control (TFRC)", International Journal of Recent Technology and Engineering, vol. 8, no. 2 Special issue 3, pp. 1598-1602.

13. Tamil Selvan, S. \& Sundararajan, M. 2019, "Performance Parameters of 3 Value 8t Cntfet Based Sram Cell Design Using H-Spice", International Journal of Recent Technology and Engineering, vol. 8, no. 2 Special issue 5, pp. 22-27.
14. Vinoth, V.V. \& Kanniga, E. 2019, "Steganographical techniques in hiding text images - system", International Journal of Recent Technology and Engineering, vol. 8, no. 2, pp. 6535-6537.

15. Saravana, S., Balaji, S., Arulselvi, S. \& John Paul Praveen, A. 2019 "Reliable power quality monitoring and protection system", International Journal of Innovative Technology and Exploring Engineering, vol. 8, no. 9 Special Issue 3, pp. 644-645.

16. Sundaramoorthy, A. \& John Wiselin, M.C. 2019, "Single patch antenna with multiple feed", International Journal of Innovative Technology and Exploring Engineering, vol. 8, no. 9, pp. 1743-1747.

17. Velavan, R., Bharanidharan, S. \& Sheeba, B. 2019, "EMF pollution Causes, effects and protection", International Journal of Innovative Technology and Exploring Engineering, vol. 8, no. 9 Special Issue 3, pp. 1166-1168.

18. Veer, R.A., Arulselvi, S. \& Karthik, B. 2019, "Construction of ensemble square classification approaches in MIMO OFDM", International Journal of Engineering and Advanced Technology, vol. 8, no. 5, pp. 2039-2041.

19. Agitha, W. \& Kaliyamurthie, K.P. 2019, "Improved energy efficient in WBAN using MAC with cloud computing", International Journal of Innovative Technology and Exploring Engineering, vol. 8, no. 8, pp. 2405-2408.

20. Kastro, G.G. \& Wiselin, M.C.J. 2019, "Design and analysis of stub loaded resonator", International Journal of Recent Technology and Engineering, vol. 8, no. 1 Special Issue4, pp. 272-283.

\section{AUTHORS PROFILE}

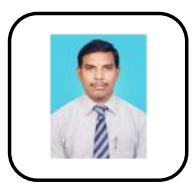

Karthik.B, Assistant Professor, Department of Electronics And Communication Engineering,, Bharath Institute of Higher Education and Research, Chennai, India..

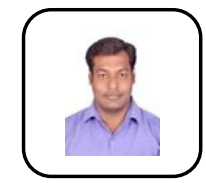

Sriram.M Assistant Professor, Department of Electronics And Communication Engineering,, Bharath Institute of Higher Education and Research, Chennai, India.

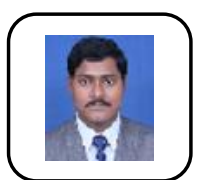

Mohan Raj.R., Assistant Professor, Department of Electronics And Communication Engineering,, Bharath Institute of Higher Education and Research, Chennai, India. 